\title{
Analysis of Environmental Pollutants as Diabetogenic Agent in the Patient Suffering from Diabetes Mellitus
}

\author{
Saima Shokat ${ }^{1}$, Riffat Iqbal ${ }^{1}$, Atif Yaqub ${ }^{1}$, Fatima Shahid ${ }^{2}$ and Samreen Riaz ${ }^{2,3 *}$ \\ ${ }^{1}$ Department of Zoology, Government College University, Lahore, Pakistan \\ ${ }^{2}$ Department of Microbiology and Molecular Genetics, University of the Punjab, Lahore, Pakistan \\ ${ }^{3}$ Pakistan Academy of Family Physician, Pakistan
}

*Corresponding author: Samreen Riaz, Department of Microbiology and Molecular Genetics, University of the Punjab; Pakistan Academy of Family Physician, Lahore, Pakistan, Tel: 00923004351979; Email: samreen.mmg@pu.edu.pk

\section{Review Article \\ Volume 6 Issue 2}

Received Date: April 15, 2021

Published Date: May 10, 2021

DOI: $10.23880 /$ doij-16000241

\section{Abstract}

Diabetes mellitus can be defined as a metabolic disorder which leads to high level of glucose in blood and lead to the diabetic patients to develop various severe and fatal health problems.. If the concentration of glucose in blood will high then it affects various body organs including eyes, nerves, foot, kidneys and heart and ultimately leads to serious complications. In this, the pancreas is not able to produce enough insulin. As a result, body becomes unable to consume nutrients appropriately.Diabetes mellitus was primarily described by Egyptians. The word "Diabetes" which means "to pass through" was 1st time used by a Greek physician Araetus of Cappodocia.According to Araetus, diabetes is associated with polyuria. While the word "Mellitus" is a Latin word which means "Sweet or Honey". Major signs and symptoms of diabetes mellitus includes Frequent urination, Excessive thirst, Excessive hunger, Sudden loss in weight, Vision problems, Slow healing of wounds, injuries and Sweating etc. Major complications of diabetes are Nephropathy Neuropathy Retinopathy Cardiovascular Disorders Amputation.There are many reasons of diabetes such as genetic factor, age, poor life style but environmental pollutants also have their role in diabetes. There are many environmental pollutant such as lead, zinc, mercury oxide, nitrate,sulphate, cadmium and Arsenic etc. The presence of arsenic (As) in drinking water has become a major public health concern around the world specially in Pakistan.Arsenic inhibits differentiation of adipocyte and mediates insulin resistance with diminutive information on arsenicosis on lipid storage and lipolysis.So the main target of research is to determine the effect of Arsenic and their control in order to decrease the number of diabetic patients.

Keywords: Glucose; Arsenic; Pakistan

\section{Introduction}

Diabetes can be described as a metabolic disorder which leads to increase level of glucose in blood and with the passage of time the possibility of diabetic patients to develop various severe and fatal health problems has been rising continuously [1]. Increase in glucose level in blood affect various body organs including eyes, nerves, foot, kidneys and heart and ultimately leads to serious complications [2].
In this, the pancreas is not able to produce sufficient insulin to maintain the level of glucose in blood. As a result, body becomes unable to consume nutrients appropriately [3]. Diabetes mellitus was initially termed by Egyptians. The word "Diabetes" which means "to pass through" was 1st time used by a Greek physician Araetus of Cappodocia (81133AD). According to Araetus, diabetes is associated with polyuria. While the word "Mellitus" is a Latin word which means "Sweet or Honey" [4]. 


\section{Diabetes \& Obesity International Journal}

\section{Signs and Symptoms of Diabetes}

Major signs and indications of diabetes mellitus are:

$\begin{array}{ll}\checkmark & \text { Frequent urination } \\ \checkmark & \text { Excessive thirst } \\ \checkmark & \text { Excessive hunger } \\ \checkmark & \text { Sudden loss in weight } \\ \checkmark & \text { Vision problems or blurred visualization } \\ \checkmark & \text { Slow healing of wounds, injuries or cuts } \\ \checkmark & \text { Sweating }\end{array}$

\section{Frequent Urination}

A person suffering from diabetes urinates more frequently when compared to non -diabetic patient. In normal persons, kidneys filter water and glucose from blood. Then glucose is reabsorbed into the blood. But in diabetic patients, level of glucose is already high in blood. So all the sugar does not reabsorb. So a large proportion of sugar resides in the kidneys. Kidney dilutes this sugar so that it is passed through the urine. This is the reason that patients urinate more frequently [5].

Excessive thirst: Excessive thirst can be described by a word polydipsia. Polydipsia is a Greek word which means "very thirsty". It is considered as an initial symptom of diabetes [6]. Excessive hunger: Polyphagia is a condition in which the person feels extreme hunger and eats a lot. The body cells' of a diabetic patient does not get sufficient energy. That's why patient feels intense hunger [7].

Weight gain: Due to excess hunger, patient eats a lot and can gain weight [8].

Blurred vision: Loss of vision, blurred vision, cataracts, bleeding in retina i.e. retinopathy, glaucoma etc are the signs and symptoms of diabetes mellitus.

Slow wound healing: Wounds, cuts, bruises etc take time to heal or sometimes does not heal properly. Excess of glucose in the body causes the slow healing of cuts or wounds [9].

Sweating: Due to diabetes, patients may suffer from perspiration or sweating [9].

\section{Causes of Diabetes}

$\beta$ cells of pancreas produce a hormone called insulin and they maintain the level of glucose in our body. But in case of diabetic patients, this insulin is not produced. As a result, the level of sugar or glucose rises in blood stream. The main causes of diabetes mellitus are due to Beta cells which are not able to produce enough insulin.

\section{Classification of Diabetes}

American Diabetes Association [10] has classified diabetes mellitus into the following 4 types:

$$
\text { Type } 1 \text { diabetes mellitus (T1DM) }
$$

\author{
$\quad$ Type 2 diabetes mellitus (T2DM) \\ $>\quad$ Gestational diabetes (GDM) \\ $>\quad$ Other types of diabetes (diabetes due to other \\ causes)
}

Type 1 diabetes mellitus: In diabetes mellitus type $1, \beta$ cell of pancreas are destroyed. So the beta cells are not able to produce insulin which ultimately increases the level of glucose [11]. In developed countries, it is considered as a very common disease in children [12]. However, this disease can arise in individuals of all ages and signs and symptoms can vary from age to age. Type 1 diabetes accounts for $5-10 \%$ cases of diabetes [13].

Type 2 diabetes mellitus: In diabetes mellitus type 2, body shows resistance against insulin or there may be deficiency of insulin in the body [14]. For many years, this type of diabetes mellitus was not able to show any indications. So it remains asymptomatic. It can be diagnosed from complications associated with it. It can be identified by checking the level or quantity of glucose in urine or blood. Sometimes obesity is also associated with type 2 diabetes mellitus which causes body to resist the effect of insulin and ultimately increases the level or quantity of glucose in blood. This disease is most common in individuals having the age of about 40 years. Out of all diabetic cases, 85-95\% cases are of type 2 diabetes which means that type 2 diabetes mellitus is very common in well settled countries. While in under developed countries, this percentage is much higher. The frequency of type 2 diabetes has been growing in a lot of countries and it has become a serious health issue. The main reasons for the occurrence of type 2 diabetes is change in diet, rise in urbanization, reduction in physical activity and unhealthy and sedentary life-style. The rate of type 2 diabetes is low in rural areas where people live a life associated with physical activity. But this rate is quite high in urban areas [15].

- Impaired glucose tolerance: Impaired glucose tolerance, also called IGT, can be defined as a condition in which the level of glucose in blood increases within 2 hours after the intake of about 75 gram of glucose. It is considered as a stage between normality and diabetes. It is an asymptomatic state. So the persons suffering from IGT are more susceptible to develop type 2 diabetes. About in $30 \%$ cases, persons suffering from IGT acquire the ability to tolerate normal glucose level within several years [16]. Like type 2 diabetes, IGT is also linked with advanced age, resistance to insulin and obesity. Studies have shown that number of individuals suffering from IGT will be 472 million by 2022 [17].

Gestational diabetes mellitus: It occurs in the period of $2^{\text {nd }}$ or $3^{\text {rd }}$ trimester and causes an increase in the quantity of glucose in blood stream. Woman does not suffer from diabetes before pregnancy but shows a few symptoms during pregnancy. Cases of GDM has been increasing lately [18]. 


\section{Diabetes \& Obesity International Journal}

Woman having gestational diabetes can suffer from:

$\begin{array}{ll}>\quad \text { High blood pressure } \\ >\quad \text { Henal disease } \\ >\quad & \begin{array}{l}\text { Damaging of nerves } \\ \text { Vision problems }\end{array}\end{array}$

Other types of diabetes: Other types of diabetes include:

- MODY: Maturity onset diabetes of the young occurs because of some mutations in gene which ultimately disrupts the production of insulin. It is also called monogenic diabetes. MODY can occurs in individuals having age below 30 . But individuals under the age of 50 years can also develop MODY [19].

- Neonatal diabetes: This type of diabetes occurs in new born babies. It occurs within six months after birth but this type of diabetes is very rare. It is also called monogenic diabetes because mutation in only one gene causes this. It is curable [20].

- Drug induced diabetes: This type of diabetes occurs due to the use of certain drugs or chemicals. Many drugs have serious side effects and ultimately they can increase the level of glucose in blood. Use of glucocorticoid and corticosteroid can cause this type of diabetes. It can be cured by taking appropriate medication and preventing the usage of medicines that may increase the quantity of glucose in blood stream.

\section{Complications Related to Diabetes}

Many serious complications are found to be associated with diabetes. Mortality rate due to diabetes and its complications has been increasing continuously. Rise in the level of glucose without any symptoms, can cause tissue damage and ultimately leads to fatal diseases. Tissue damage can occur in many organs including eyes, kidneys, nerves etc. Diabetes can also lead to high blood pressure, stroke and myocardial infarction. It can also increase lipid content of the body and can affect small blood vessels.

\section{Major complications}

Major complications of diabetes are:

$\begin{array}{ll}> & \text { Nephropathy } \\ > & \text { Retinopathy } \\ > & \text { Cardiovascular disorders } \\ & \text { Amputation [21] }\end{array}$

- Nephropathy: Nephropathy are very common in individuals suffering from type 1 or type 2 diabetes mellitus. Nephropathy can be defined as a condition in which kidney damage and ultimately kidney failure occurs. In most of the cases, kidney failure occurs due to diabetes. Nephropathy has five stages and end stage renal disease (ESRD) is the last stage. Diabetic nephropathy leads to ESRD in which the person needs dialysis or kidney transplantation [22]. This disease develops slowly and takes 20 to 22 years to show symptoms.

- Neuropathy: Diabetes also affects our peripheral nervous system and damages our peripheral nerves. As a result, loss of sensation (feeling) or numbness can be felt in the feet and hands. But numbness in the feet is more common. Neuropathy also causes severe pain and ulcers in foot [23]. Neuropathy can lead to the loss of foot or toe. It can also cause urinary tract infection, low blood pressure, digestion problems and increased sweating etc. Neuropathy can be prevented by controlling the level of glucose in blood and by taking care of feet [24].

- Retinopathy: Diabetes has become the cause of loss of vision. It can be diagnosed and treated easily. As type 2 diabetes mellitus stays undiagnosed for many years, so when type 2 diabetes is diagnosed, many people already have this disease. In this, blood vessels in retina are damaged. As a result, loss of vision occurs. Laser surgery is used to treat retinopathy [25].

- Cardiovascular disorders: It is the major complication linked to diabetes and it is the major and most common cause of deaths in persons suffering from diabetes [26]. About $50-80 \%$ deaths of diabetic patients are due to cardiovascular disorders. The chances of diabetic patients are $4 \%$ higher to get cardiovascular disorders as compared to normal individuals. The rate of myocardial infarction and sudden failure of heart is also increasing.

- Amputation: Amputation is the process of removing a limb by surgery. The main reason for amputation is poor circulation of blood. Diabetes effects arteries and peripheral nerves. As a result, the blood does not flow properly and the tissue does not get sufficient nutrients and oxygen. Thus diabetes cause infection and ulcer formation in the foot and ultimately compels the patient for the amputation of the foot, toe or limb. The chances of amputation are 25 times more in individuals suffering from diabetes [27].

\section{Environmental Pollutant as Diabetogenic Agent}

There are so many causes of diabetes like poor life style, genetic factor, environmental pollutant etc. Environmental pollutants have been present throughout human history. Pollutant is a substance or energy introduced into the environment that has undesired effects, or adversely affects the usefulness of a resource. A pollutant may cause long- or short-term damage by changing the growth rate of plant or animal species, or by interfering with human amenities, comfort, health, or property values. The conventional pollutants such as biological toxins and heavy metals and newly synthesized chemicals are increasingly becoming 


\section{Diabetes \& Obesity International Journal}

part of our environment. Often, the risks to humans and the environment are studied long after they are commercialized. Examples of such chemicals are pesticides, Cadmium, Arsenic carbon dioxide, Sulphur dioxide, nitrate, mercury, furan lead and antibiotics. In the future, as technology advances, even more complicated risks are anticipated with novel substances such as nanomaterials. It is not possible to describe all the pollutants and toxins currently in place. Instead, we would like to focus on some of the most important environmental pollutant summarize them, their properties and suspected risks will be documented.

There are too many chemicals present in the environment that are linked with diabetes. There are many chemicals that effect sensitivity of insulin and effect beta cells then trigger type 2 diabetes. POPs, dioxins, BPA and arsenic are chemicals that play their role to make a person diabetic and arsenic is the chemical of great interest. Pops (Pcbs, dioxins, TCDD), Phthalate, Bisphenol A, Arsenic, Dioxins, Persistent organic pollutants are mostly known as POPs, it is a major class of environmental pollutants. POPs includes a great variety of chemicals that are may be anthropogenic or may be accidentally released in any industrial process.

\section{Role of Arsenic in Diabetes}

Arsenic is a naturally occurring toxic metalloid of global concern. It can be present as inorganic and organic forms in the environment. Inorganic forms of arsenic are the dominan in surface and groundwater reservoirs and are more toxic than the organic forms. Arsenic can be easily solubilized in groundwater's, due to its $\mathrm{pH}$, redox conditions, temperature, and solution composition. The present study reviewed the effects of arsenic exposure on the risk and potential etiologic mechanisms of diabetes. It has been observed that inflammation, oxidative stress, and apoptosis contribute to the pathogenesis of arsenic-induced diabetes. Though arsenic is known to cause diabetes through different mechanisms, the role of adipose tissue in diabetes is still unclear. This review exhibited the effects of arsenic on the metabolism and signaling pathways within adipose tissue (such as sirtuin 3 [SIRT3]- forkhead box 03 [FOXO3a], mitogen-activated protein kinase [MAPK], phosphoinositidedependant kinase-1 [PDK-1], unfolded protein response, and C/EBP homologous protein [CHOP10]) [28-52].

\section{References}

1. Baena-Díez JM, Peñafiel J, Subirana I, Ramos R, Elosua R, et al. (2016) Risk of cause-specific death in individuals with diabetes: a competing risks analysis. Diabetes Care 39(11): 1987-1995.

2. WHO (2019) Global health risks: mortality and burden of disease attributable to selected major risks. World Health Organization, Geneva.

3. Bharti A, Chawla SPS, Kumar S, Kaur S, Soin D, et al. (2019) Asymptomatic bacteriuria among the patients of type 2 diabetes mellitus. Journal of Family Medicine and Primary Care 8(2): 539-543.

4. Ahmed AM (2002) History of diabetes mellitus. Saudi medical journal 23(4): 373-378.

5. Fleisher GR, Ludwig S (2017) Textbook of pediatric emergency medicine, Lippincott Williams \& Wilkins.

6. Porth C (2015) Pathophysiology: Concepts of altered health states, Volume-1, Lippincott Williams \& Wilkins.

7. Berthoud HR, Lenard NR, Shin AC (2013) Food reward, hyperphagia, and obesity. Am J Physiol Regul Integr Comp Physiol 300(6): R1266-R1277.

8. Association AD (2016a) 3. Foundations of care and comprehensive medical evaluation. Diabetes care 39(S1): S23-S35.

9. Buch PJ, Chai Y, Goluch ED (2019) Treating Polymicrobial Infections in Chronic Diabetic Wounds. Clinical microbiology reviews 32(2): e00091-e00118.

10. Association AD (2016b) Erratum. Classification and diagnosis of diabetes. Sec. 2. In standards of Medical Care in Diabetes-2016. Diabetes Care 2016; 39(S1): S13-S22. Diabetes care 39(9): 1653.

11. Atkinson MA, Maclaren NK (2014) The pathogenesis of insulindependent diabetes mellitus. New England journal of medicine 331(21): 1428-1436.

12. La Porte R, Matsushima M, Chang Y (1995) Prevalence and incidence of insulin dependent diabetes: In Diabetes in America, National Diabetes Data Group, National Institutes of Health.

13. Association AD (2019) Diagnosis and classification of diabetes mellitus. Diabetes care 33(S1): S62-S69.

14. Tuomilehto J, Lindström J, Eriksson JG, Valle TT, Hämäläinen $\mathrm{H}$, et al. (2017)Prevention of type 2 diabetes mellitus by changes in lifestyle among subjects with impaired glucose tolerance. New England Journal of Medicine 344(18): 1343-1350.

15. Shaw JE, Sicree RA, Zimmet PZ (2010) Global estimates of the prevalence of diabetes for 2010 and 2030. Diabetes research and clinical practice 87(1): 4-14.

16. Alberti K (2006) The clinical implications of impaired 


\section{Diabetes \& Obesity International Journal}

glucose tolerance. Diabetic Medicine 13(11): 927-937.

17. Unwin N, Shaw J, Zimmet P, Alberti K (2012) Impaired glucose tolerance and impaired fasting glycaemia: the current status on definition and intervention. Diabetic medicine 19(9): 708-723.

18. Metzger BE, Buchanan TA, Coustan DR, De Leiva A, Dunger DB, et al. (2007) Summary and recommendations of the fifth international workshop-conference on gestational diabetes mellitus. Diabetes care 30(S2): S251-S260.

19. Katra B, Klupa T, Skupien J, Szopa M, Nowak N, et al. (2010) Dipeptidyl peptidase-IV inhibitors are efficient adjunct therapy in HNF1A maturity-onset diabetes of the young patients-report of two cases. Diabetes technology \& therapeutics 12(4): 313-316.

20. Caburnay CA, Graff K, Harris JK, McQueen A, Smith M, et al. (2015) Evaluating Diabetes Mobile Applications for Health Literate Designs and Functionality, 2014. Preventing chronic disease 12: 140433.

21. Casey B, Trainor RJ, Orendi JL, Schubert AB, Nystrom LE, et al. (1997) A developmental functional MRI study of prefrontal activation during performance of a go-no-go task. Journal of cognitive neuroscience 9(6): 835-847.

22. Foley RN, Collins AJ (2007) End-stage renal disease in the United States: an update from the United States Renal Data System. Journal of the American Society of Nephrology 18(10): 2644-2648.

23. Kazamel M, Dyck PJ (2015) Sensory manifestations of diabetic neuropathies: anatomical and clinical correlations. Prosthet Orthot Int 39(1): 7-16.

24. Smith EML, Pang H, Cirrincione C, Fleishman S, Paskett ED, et al. (2018) Effect of duloxetine on pain, function, and quality of life among patients with chemotherapyinduced painful peripheral neuropathy: a randomized clinical trial. Jama 309(13): 1359-1367.

25. Davis TM, Stratton IM, Fox CJ, Holman RR, Turner RC, et al. (1997) UK Prospective Diabetes Study 22: effect of age at diagnosis on diabetic tissue damage during the first 6 years of NIDDM. Diabetes care 20(9): 1435-1441.

26. Harris MI, Flegal KM, Cowie CC, Eberhardt MS, Goldstein DE, et al. (1998) Prevalence of diabetes, impaired fasting glucose, and impaired glucose tolerance in US adults: the Third National Health and Nutrition Examination Survey, 1988-1994. Diabetes care 21(4): 518-524.

27. Drake A, Smith A, Betts P, Crowne E, Shield J (2002) Type 2 diabetes in obese white children. Archives of disease in childhood 86(3): 207-208.
28. Farkhondeh T, Samarghandian S, Azimi-Nezhad M (2019) The role of arsenic in obesity and diabetes. Journal of cellular physiology 234(8): 12516-12529.

29. Franco AVM (2005) Recurrent urinary tract infections. Best Practice \& Research Clinical Obstetrics \& Gynaecology 19(6): 861-873.

30. Gleichmann H, Zörcher B, Greulich B, Gries F, Henrichs $\mathrm{H}$ (1984) Correlation of islet cell antibodies and HLADR phenotypes with diabetes mellitus in adults. Diabetologia 27(1): 90-92.

31. Goetzl L (2002) ACOG Committee on Practice BulletinsObstetrics. ACOG Practice Bulletin. Clinical Management Guideline for ObstetricianGynecologists Number 36, July 2002. Obstetric analgesia and anesthesia. Obstet Gynecol 100(1): 177-191.

32. Gorter KJ, Hak E, Zuithoff NP, Hoepelman AI, Rutten GE (2010) Risk of recurrent acute lower urinary tract infections and prescription pattern of antibiotics in women with and without diabetes in primary care. Family practice 27(4): 379-385.

33. Groop LC, Bottazzo GF, Doniach D (1986) Islet cell antibodies identify latent type I diabetes in patients aged 35-75 years at diagnosis. Diabetes 35(2): 237-241.

34. Diabetes Prevention Program Research Group, William C Knowler, Sarah E Fowler, Richard F Hamman, Costas A Christophi, et al. (2009) 10-year follow-up of diabetes incidence and weight loss in the Diabetes Prevention Program Outcomes Study. The Lancet 374(9702): 16771686.

35. Riaz S, Rana S (2014) Analysis of Uropathogenes among type II diabetic patients in Pakistani population. Advances in Diabetes and Metabolism 2(2): 31-41.

36. Riaz S (2015) Study of protein biomarkers of diabetes mellitus type 2 and therapy with vitamin B1. Journal of diabetes research, Article ID: 150176.

37. Samreen Riaz, Saadia Shahzad Alam (2012) Study of diabetic hypertensive nephropathy in the local population of pakistan. Diabetic Nephropathy, Professor of Medicine, Faculty of Medicine, Université de Montréal, Chief, Laboratory of Molecular Nephrology and Endocrinology, CRCHUM- Hôtel-Dieu Hôpital Montréal, Québec, Canada, pp: 147-166.

38. Samreen Riaz (2012) Protein Biomarkers for diabetes mellitus type 2. Biomarker. Blanchette Rockefeller Neurosciences Institute, West Virginia University, USA.

39. Samreen Riaz (2014) Obesity as a Risk Factor for 
Diabetes \& Obesity International Journal

Diabetes Mellitus in the Local Population of Pakistan. Universal Journal of Clinical Medicine 2(3): 58-64.

40. Samreen Riaz (2014) Evaluation and Analysis of Human Folate levels in Pakistani diabetic Population. International Journal of Scientific \& Engineering Research 5(12): 1572-1576.

41. Samreen Riaz (2015) Study of protein biomarkers of diabetes mellitus type 2 and therapy with Vitamin B1. Journal of Diabetes Research, Article ID: 150176.

42. Shaw JE, Sicree RA, Zimmet PZ (2010) Global estimates of the prevalence of diabetes for 2010 and 2030. Diabetes research and clinical practice 87(1): 4-14.

43. Scott (2020) What is the difference between type 1 and type 2 diabetes? Sutherland Podiatry Centre.

44. Sewify M, Nair S, Warsame S, Murad M, Alhubail A, et al. (2016) Prevalence of urinary tract infection and antimicrobial susceptibility among diabetic patients with controlled and uncontrolled glycemia in Kuwait. Journal of diabetes research, Article ID: 6573215.

45. Shifflett T (2018) Diabetes and Urinary Tract InfectionsThings You Need To Know. Healthgrades.

46. Smith E M L, Pang H, Cirrincione C, Fleishman S, Paskett ED, et al, (2013) Effect of duloxetine on pain, function, and quality of life among patients with chemotherapyinduced painful peripheral neuropathy: a randomized clinical trial. Jama 309(13): 1359-1367.

47. Soo Park B, Lee SJ, Wha Kim Y, Sik Huh J, Il Kim J, et al. (2006) Outcome of nephrectomy and kidney-preserving procedures for the treatment of emphysematous pyelonephritis. Scandinavian journal of urology and nephrology 40(4): 332-338.

48. Sussman EJ, Tsiaras WG, Soper KA (1982) Diagnosis of diabetic eye disease. Jama 247(23): 3231-3234.

49. Nordstrom DK (2002) Worldwide occurrences of arsenic in ground water. American Association for the Advancement of Science.

50. Yashima H, Terasaki M, Kushima H, Hirano T (2019) Emphysematous cystitis in an elderly Japanese patient with type 2 diabetes mellitus. Clinical case reports 7 (3): 585-586.

51. Zimmet P, Alberti K, Shaw J (2001) Global and societal implications of the diabetes epidemic. Nature 414(6865): 782-787.

52. Zimmet P, Dowse G, Finch C, Serjeantson S, King H (1990) The epidemiology and natural history of NIDDM-lessons from the South Pacific. Diabetes/metabolism reviews 6(2): 91-124. 